Report DOE DE-FG05-86ER25017

$$
\text { DOE/ER } \mid 2.5017-T /
$$

Research on Trust-Region Algorithms for Nonlinear Programming

John E. Dennis, Jr. Richard A. Tapia

Department of Computational and Applied Mathematics - MS 134

Rice University

P.O. Box 1892

Houston, Texas 77251-1892

19 December 1995

Final Technical Report for Period 1 January 1990 - 31 December 1992

Prepared for

Dr. Frederick A. Howes

ER-30

19901 Germantown Road

Washington, DC 20874 


\section{DISCLAIMER}

Portions of this document may be illegible in electronic image products. Images are produced from the best available original document. 


\section{DISCLAIMER}

This report was prepared as an account of work sponsored by an agency of the United States Government. Neither the United States Government nor any agency thereof, nor any of their employees, makes any warranty, express or implied, or assumes any legal liability or responsibility for the accuracy, completeness, or usefulness of any information, apparatus, product, or process disclosed, or represents that its use would not infringe privately owned rights. Reference herein to any specific commercial product, process, or service by trade name, trademark, manufacturer, or otherwise does not necessarily constitute or imply its endorsement, recommendation, or favoring by the United States Government or any agency thereof. The views and opinions of authors expressed herein do not necessarily state or reflect those of the United States Government or any agency thereof. 


\title{
Research on Trust-Region Algorithms for Nonlinear Programming
}

\author{
J.E. Dennis, Jr. $\quad$ R.A. Tapia
}

December 1992

\section{ABSTRACT}

The goal of the research proposed was to develop and test effective, robust algorithms for general nonlinear programming (NLP) problems, particularly large or otherwise expensive NLP problems. We will discuss the research conducted under this grant over the three year period January 1990 - December 1992. We will also describe the current and future directions of our research.

\section{MAJOR ACCOMPLISHMENTS}

\subsection{Interior-point methods for linear programming}

Richard Tapia and his collaborators have investigated the nonlinear structure of interior point methods for linear programming problems. This work settled a number of important open questions concerning the relation of interior-point methods to optimization methods for nonlinear problems.

Some of the research was of a theoretical nature, such as the development of a number of provably polynomial-time interior-point algorithms for LP and proofs of local fast rates of convergence. The latter were based on recognizing the connection between interior-point methods for LP and Newton's method. Our work on indicators in interior-point methods for LP, on the other hand, has produced a promising computational method. Indicators were first proposed by Tapia for NLP, and are a method for identifying binding inequality constraints.

This research represents contributions across all the algorithmic aspects of interior-point methods. The understanding we have gained of interior-point methods for LP forms the basis of our current and future work on interior-point methods for NLP. Moreover, in practice, many large-scale NLP are solved using successive linear programming (SLP), where the LP subproblem is posed with $\mathrm{L}$ - norm constraints. Interior-point methods are well suited for use in SLP, since they allow for a very natural approximate solution to the LP subproblem.

\subsection{Trust-region SQP Newton's method for large scale, sparse, equality constrained NLP}

The research in this area has produced a robust algorithm for large scale equality constrained optimization that has proven effective in the numerical trials to date. A powerful convergence theory for the algorithm was developed in Cristina Maciel's Ph.D. dissertation, under the direction of John Dennis and Mahmoud El-Alem. Michael Lewis 
has implemented this algorithm and applied it successfully to inverse problems in flow in porous media.

The novel idea in the large scale algorithm is the use of the conjugate reduced gradient method with the Steihaug-Toint dogleg approach as a means of solving the large, sparse $\mathrm{SQP}$ subproblem. This avoids the prohibitive expense of matrix factorizations, which is crucial, for instance, in the flow in porous media applications.

The merit function used in this algorithm is the augmented Lagrangian, where the penalty weight is updated according to a scheme of El-Alem. The convergence theory allows us wide latitude in the choice of multiplier estimates; we use one that is based on a division of the variables into basic and non basic variables. This choice of multiplier is inexpensive and yet does not lead to any degradation of the algorithm's performance.

\section{OTHER ACCOMPLISHMENTS}

\subsection{Trust-region, sequential quadratic programming (SQP), Newton's method for general, equality constrained, nonlinear programming}

The main effort in this area was the continued development of trust-region algorithms for equality constrained NLP along the lines of the now well-known Celis-Dennis-Tapia (CDT) trust-region method. The CDT was originally developed and implemented under DOE sponsorship.

One of our major accomplishments in this area has been the theoretical and computational development of a less expensive trust-region subproblem than in the original CDT algorithm. In the original CDT approach, the trust-region subproblem involved the minimization of a quadratic model of the Lagrangian over the intersection of the trust-region and a region associated with improvement in linearized feasibility. This subproblem was difficult to solve, particularly when the quadratic model was not convex. To remedy this, we developed a less expensive subproblem that requires only the minimization of the model over a two-dimensional subspace. this new subproblem, the subject of Karen Williamson's Ph.D. dissertation, has proven robust and very efficient. Under separate funding, a production implementation of the algorithm is being developed.

\subsection{A unified approach to global convergence of trust-region methods for nonsmooth optimization}

This was the subject of Shou-Bai Li's Ph.D. dissertation, written under the direction of both John Dennis and Richard Tapia. This work unifies the body of convergence theory developed by various authors and identifies the essential components of the theory necessary to insure convergence.

\subsection{SQP augmented Lagrangian BFGS algorithms for constrained optimization}

In this work, we developed an effective BFGS secant method for constrained optimization based on a family of BFGS secant updates proposed by Tapia. This earlier work was also 
supported by DOE. With our globalized BFGS secant method, we obtained impressive numerical results, superior to those of Powell's damped BFGS secant method for constrained optimization, the secant update algorithm of choice for the past 10 years. We also presented a convergence theory for our new BFGS secant method.

\section{CURRENT AND FUTURE DIRECTIONS}

Our research is directed towards the development of optimization algorithms to solve a class of geophysical inverse problems that include petroleum reservoir and aquifer characterization problems. These problems are of importance to the DOE mission because they are crucial in environmental cleanup and in managing oil and groundwater resources. We will cooperate with other researchers at Rice, Mary Wheeler's flow in porous media simulation group in our department and Phil Bedient's groundwater resources group in the Rice Environmental Science and Engineering Department, for the expertise in modeling, simulation, and data needed to ensure the relevance of our work. We see the following directions for this project.

\subsection{Applications to flow in porous media}

Under separate funding, the Texas Geophysical Parallel Computation Project, we have begun applying our equality constrained optimization methods to inverse problems in flow in porous media. The Texas Geophysical Parallel Computation Project is indirectly supported by DOE; its funding ultimately derives from a DOE oil overcharge lawsuit settlement fund.

The inverse problems we are investigating in this work are best posed as very large-scale, computational intensive NLP problems with large numbers of equality and inequality constraints. As such, these applications are providing impetus to our development of trustregion NLP methods.

We choose to view simulations - the partial differential equations that describe subsurface flow, in the case of the geophysical inverse problems - as constituting equality constraints. These constraints we eliminate in various ways to produce NLP formulations of the inverse problem that can be solved more efficiently than the more immediate formulation. However, this approach requires that we have robust, efficient NLP methods for very large problems.

In order to produce sensible and accurate images of subsurface structure, these inverse problems also require some from of regularization of the solution in order to overcome "illposedness." We believe that this can best be done using inequality constraints, rather than through some penalization method such as Tikhonov regularization, which require the estimation of an unknown but crucial weighting parameter. Explicit inequality constraints can be devised to give very precise control over the regularization of the solution in a manner that is physically sensible for the problem.

\subsection{Computational parallelism and nonlinear programming}

We are already taking advantage, in novel ways, of domain decomposition methods for 
partial differential equations. Rather than treating domain decomposition methods as a convenient way to solve the attendant partial differential equation in the geophysical inverse problems we are investigating, we are actually integrating the domain decomposition method into the formulation of the NLP.

\section{PRINCIPAL PROJECT PERSONNEL}

\subsection{J.E. Dennis, Jr., Noah G. Harding Professor of Mathematical Sciences}

Role in the project

Principal investigator

Principal area of research and expertise

Design and analysis of practical computer algorithms for nonlinear optimization problems.

\section{Percentage of time devoted to project}

$$
8.33 \%
$$

\section{Education}

Ph.D. $\quad$ Mathematics, University of Utah, 1966

M.S. $\quad$ Mathematics, University of Miami, Florida, 1964

B.S. $\quad$ Engineering, University of Miami, Florida, 1962

\section{Relevant professional employment history}

1992- Chairman, Department of Computer Science, Rice University

1989-1992 Chairman, Department of Mathematical Sciences, Rice University

1988-1993 Adjunct Professor, Combinatorics and Optimization, Waterloo

1986 University

Fulbright Lecturer to Argentina and Professor, University of Buenos Aires

\section{Relevant professional activities and honors}

1989- Editor-in-Chief and Founder, SIAM Journal on Optimization

1989-1992 Chairman, SIAM Activity Group on Optimization

1992

1990

Committee on Visitors, NSF Applied Analysis Program

Member, Editorial Board, Journal for Numerical Linear Algebra with Applications 
1985-1991 Member, Council of the Society for Industrial and Applied Mathematics

1988- Member, Program Committee of International consortium for Industrial and Applied Mathematics

1988-1991 Advisory Board, Mathematical Sciences Research Institute, Cornell University

1987- Member, International Program Committee of Mathematical Programming Society

1986-1989 Co-Editor, Mathematical Programming

1986-1988 Member, National Research Council Committee on Recommendations for U.S. Army Basic Scientific Research

1986-1987 Co-Organizer, SIAM International Optimization Conference

1985-1988 Member, Executive Committee, Council of the Society for Industrial and Applied Mathematics

1974-1989 Member, Editorial Board of Mathematical Programming

1985-1987 External Member, Search Committee for Clements Chair of Mathematics at Southern Methodist University

\subsection{R.A. Tapia, Noah G. Harding Professor of Mathematical Sciences}

\section{Role in the project}

Principal investigator.

Principal area of research and expertise

Numerical analysis in general. In particular, mathematical optimization theory and iterative methods for nonlinear problems. Current research interest include interiorpoint methods for linear and nonlinear programming.

\section{Percentage of time devoted to project}

$8.33 \%$

\section{Education}

Ph.D. Mathematics, University of California, Los Angeles, 1967

M.A. Mathematics, University of California, Los Angeles, 1966

B.A. Mathematics, University of California, Los Angeles, 1961

\section{Relevant professional employment history}

1991- Noah G. Harding Professor of Mathematical Sciences, Rice

1989- University Director of Minority Affairs, Office of Graduate Studies, 
1989- Rice University

- Director of Education and Minority Programs, Center for Research

1976- $\quad$ Prefersor Computation, Rice University

1986-1988 Lecturer, Department of Community Medicine, Baylor College of Medicine

\section{Relevant professional activities and honors}

1992

1992

1992

1992

1992

1991

1991

1991

1990

1990-1991

1990

$1990-$

1990-1991

1990

1990

1990

1989

$1989-$

1988

$1981-$

1978-1991
Inducted into the National Academy of Engineering

Honored at the Hispanic Engineering National Achievement Awards Conference as the first Mexican American elected to the National Academy of Engineering Listed in Who's Who in America Member, Rewards and Evaluations Committee, Joint Policy Board on Mathematics

Member, Mathematical Science Education Board, National Academy of Sciences

Listed in Who's Who in the South and Southwest

Listed in Who's Who in Hispanic America

Noah G. Harding Professor, Rice University

George R. Brown Teaching Award, Rice University

Co-editor, Proceedings of the Fifth Mexico-United States

Workshop on Numerical Analysis

Editor, SIAM Journal on Optimization

Editor, Special issue of Linear Algebra and Its Applications dedicated to interior point methods for linear programming Member, American Mathematical Society Committee on Education Member, Strategic Planning Task Force, American Mathematical Society

Hispanic Engineer National Achievement Award for Education The Joint MAA-SIAM Invited Address: "Interior-Point Methods for Linear Programming: An Overview," Joint Mathematics Meeting, Columbus, Ohio

Named one of twenty most influential leaders in minority math education by the National Research Council, Washington, DC Instructor and Director, NSF Chautauqua short course, "InteriorPoint Methods for Linear Programming," Portland, Oregon Member, SIAM Board of Trustees Centennial Lecture: "The Emergence of Numerical Optimization," SIAM National Meeting, Minneapolis, Minnesota Editor, Journal of Optimization Theory and Applications

Editor, SIAM Journal on Numerical Analysis

\section{PARTICIPATING PROFESSIONALS}

6.1 Graduate students. The following graduate students participated in the project's research in the course of their graduate education. 
- Natalia Alexandrov, Ph.D. expected 1993

[supported 10-1-92 - present]

- Amr El-Bakry, Ph.D. 1991, "On the Role of Indicators in Identifying Zero Variables in Linear Programming"

[supported 5-16-90 - 5-15-91]

- $\quad$ Eva Lee, Ph.D. expected 1993

[supported 6-1-91 - 7-31-91]

- $\quad$ Shou-Bai Li, Ph.D. 1989, "Global Convergence of Trust-Region Methods for Minimizing a Nondifferentiable Function"

- Cristina Maciel, Ph.D. 1992, "A Global Convergence Theory for a General Class of Trust-Region Algorithms for Equality Constrained Optimization" [supported 7-1-90 - 8-15-92]

- $\quad$ Kurt Overley, Ph.D. 1991, “A New Secant Update for Nonlinear Constrained Optimization

- $\quad$ Marcela Rosemblun, M.A. expected 1993

- Catherine Samuelsen, Ph.D. 1992, "The Dikin Karmarkar Principle for Steepest Descent"

6.2 Research staff. The following members of the research staff at rice University also participated in the project's research. Dr. Li and Dr. El-Bakry assisted Richard Tapia and John Dennis in the development and implementation of optimization algorithms.

- Amr El-Bakry (visiting Rice University from the University of Alexandria) [supported 3.0 months of 1991]

- $\quad$ Guangye Li (visiting Rice University from Cray Research) [supported 1.5 months of 1991]

6.3 Major collaborators. The following is a list of researchers at Rice University who have participated in significant collaborative work with the principal investigators on this project.

- Mahmoud El-Alem (University of Alexandria) - trust-region methods for nonlinear programming

- $\quad$ Amr El-Bakry (Rice University) - interior-point methods

- Clovis Gonzaga (University of Rio de Janeiro) - interior-point methods

- Michael Lewis (Rice University) - optimization of systems governed by PDE

- $\quad$ Florian Potra (University of Iowa) - interior-point methods

- Virginia Torczon (Rice University) - direct search methods

- Karen Williamson (Rice University) - trust-region methods for nonlinear programming

- $\quad$ Yinyu Ye (University of Iowa) - interior-point methods 
- Yin Zhang (University of Maryland) - interior-point methods

\section{PROJECT HISTORY}

A summary of current and past DOE support for J.E. Dennis and R.A. Tapia

Project: Trust-region Algorithms for Nonlinear Programming

Principal Investigators: J.E. Dennis and R.A. Tapia

Project Period: January 1, 1990 - December 31, 1992

$\begin{array}{cccc}\text { Period } & \text { Total Funding } & \text { Research Funding } & \text { Overhead } \\ 1 / 92-12 / 92 & \$ 104,576 & \$ 72,785 & \$ 31,791 \\ 1 / 91-12 / 91 & \$ 104,279 & \$ 72,560 & \$ 31,719 \\ 1 / 90-12 / 90 & \$ 97,666 & \$ 66,440 & \$ 31,226\end{array}$

Project: Texas Geophysical Parallel Computation Project

Principal Investigators: J.E. Dennis

Project Period: July 1, 1990 - July 31, 1994

$\begin{array}{ccc}\text { Period } & \text { Annual Funding } & \text { Direct Research Funding } \\ 7 / 90-7 / 94 & \$ 75,000 & \$ 75,000\end{array}$

Project: Quasi-Newton Methods for Large-Scale Nonlinear Equations and Constrained Optimization

Principal Investigators: J.E. Dennis and R.A. Tapia

Project Period: July 1, 1986 - June 30, 1989

$\begin{array}{cccc}\text { Period } & \text { Total Funding } & \text { Research Funding } & \text { Overhead } \\ 7 / 88-6 / 89 & \$ 98,399 & \$ 67,862 & \$ 30,337 \\ 7 / 87-6 / 88 & \$ 98,399 & \$ 72,810 & \$ 25,589 \\ 7 / 86-6 / 87 & \$ 95,266 & \$ 74,172 & \$ 21,094\end{array}$

\section{PROJECT OUTPUT}

\subsection{Optimization codes}

- IP5: Primal-dual predictor-corrector interior-point code for large scale linear programming problems.

- $\quad$ PDS: A parallel direct search method for unconstrained minimization.

- IBG: Parallel, large-scale nonlinear programming code for parameter identification for flow in porous media applications. 


\subsection{Reports emanating from this project}

- $\quad$ "A Curvilinear Search Using Tridiagonal Secant Updates for Unconstrained Optimization," SIAM Journal on Optimization, 1 (1991), pp. 333-357, J.E. Dennis, N. Echebest, M.T. Guardarucci, J.M. Martinez, H.D. Scolnik, and C. Vacchino.

- "A Global Convergence Theory for General Trust-Region-Based Algorithms for Equality Constrained Optimization," Technical Report 92-28, J.E. Dennis, M. ElAlem, and M.C. Maciel.

- "A Quadratically Convergent $\mathrm{O}(\sqrt{ } \mathrm{nL})$-Iteration Algorithm for Linear Programming," to appear in Mathematical Programming, O. Güler, R.A. Tapia, Y. Ye, and Y. Zhang.

- "A Robust Trust-Region Algorithm for Nonlinear Programming," Technical Report 90-22, K. Williamson.

- “A Superlinearly Convergent $\mathrm{O}(\sqrt{ } \mathrm{nL})$-Iteration Algorithm for Linear Programming," Technical Report 91-22, R.A. Tapia, Y. Ye, and Y. Zhang.

- $\quad$ "A Superlinearly Convergent Polynomial Primal-Dual Interior-Point Algorithm for Linear Programming," to appear in SIAM Journal on Optimization, R.A. Tapia and Y. Zhang.

- " "A Study of Indicators for Identifying Zero Variables in Interior-Point Methods," to appear in SIAM Review, A. El-Bakry, R.A. Tapia, and Y. Zhang.

- "A Unified Approach to Global Convergence of Trust Region Methods for Nonsmooth Optimization," to appear in Mathematical Programming, J.E. Dennis, Shou-Bai Li, and R.A. Tapia.

- $\quad$ "An Algorithm Based on a Convenient Trust-Region Subproblem for Nonlinear Programming," J.E. Dennis, J.M. Martinez, R.A. Tapia, and K.A. Williamson, in draft form.

- "An Interior-Point Method with Polynomial Complexity and Superlinear Convergence for Linear Complementarity Problems," Technical Report 91-23, J. Ji, F. Potra, R.A. Tapia, and Y. Zhang.

- $\quad$ "An Optimal Basis Identification Technique for Interior-Point Linear Programming Algorithms," Linear Algebra and Its Applications, 152 (1991), pp 343-363, R.A. Tapia and Y. Zhang.

- "An SQP Augmented Lagrangian BFGS Algorithm for Constrained Optimization," SIAM Journal on Optimization, 2 (1992), pp. 210-241, R.H. Byrd, R.A. Tapia, and $\mathrm{Y}$. Zhang.

- "Cubically Convergent Method for Locating a Nearby Vertex in Linear Programming," Journal of Optimization Theory and Applications, 67 (1990), pp. 217-225, R.A. Tapia and Y. Zhang. 
- "Numerical Comparisons of Local Convergence Strategies for Interior-Point Methods in Linear Programming," Technical Report 91-18, A.S. El-Bakry, R.A. Tapia, and Y. Zhang.

- "On the Convergence of the Iteration Sequence in Primal-Dual Interior-Point Methods," Technical Report 91-24, R.A. Tapia, Y. Ye, and Y. Zhang.

- "On the Convergence of Interior-Point Methods to the Center of the Solution Set in Linear Programming," Technical Report 91-30, R.A. Tapia and Y. Zhang.

- "On the Superlinear and Quadratic Convergence of Primal-Dual Interior-Point Linear Programming Algorithms," SIAM Journal on Optimization, 2 (1992), pp. 304-323, J.E. Dennis, R.A. Tapia, and Y. Zhang.

- "On the Superlinear Convergence of Interior-Point Algorithms for a General Class of Problems," to appear in SIAM Journal on Optimization, R.A. Tapia, F. Potra, and Y. Zhang.

- $\quad$ "Sizing the BFGS and DFP Updates: A Numerical Study," to appear in Journal of Optimization Theory and Applications, M. Contreras and R.A. Tapia.

- "Solution of a Trust-Region Subproblem for Nonlinear Programming: Minimizing a Non-convex Quadratic Subject to Two Quadratic Constraints," Technical Report 90-23, K. Williamson.

- "Superlinear and Quadratic Convergence of Primal-Dual Interior-Point Methods for Linear Programming Revisited," Journal of Optimization Theory and Applications, 73 (1992), pp. 229-242, R.A. Tapia and Y. Zhang.

- "The Dikin-Karmarkar Principle for Steepest Descent: Avoiding Short Steps," Technical Report 91-20, C.M. Samuelsen and R.A. Tapia. 